\title{
GROTOWSKI E A MEMÓRIA SOCIAL DA POLÔNIA ${ }^{1}$
}

\author{
Melissa da Silva Ferreira ${ }^{2}$
}

\begin{abstract}
Resumo
Neste artigo pretende-se analisar as condições histórico-sociais em que Jerzy Grotowski esteve inserido, bem como sua relação com a tradição, a história e a memória social e mítica da Polônia. Para isso, elementos da biografia de Grotowski, da história social da Polônia, e conteúdos do imaginário simbólico polonês são colocados em evidência, com o intuito de delinear o contexto de surgimento, sobrevivência e encerramento das atividades e experiências do Teatr-Laboratorium.
\end{abstract}

Palavras-chave: Jerzy Grotowski, memória social, tradição mítica.

\section{Abstract}

This article aims at the analysis of Jerzy Grotowski's historical and social context and his relationship with Polish tradition, history, mythical and social memory. For this purpose, elements of Grotowski's biography and Polish social history and symbolic imaginary are revealed to delineate the source context, enduring and closing activities and experiences of Teatr-Laboratorium.

Keywords: Jerzy Grotowski, social memory, mythical tradition.

Apesar do trabalho de Grotowski estar situado como um dos expoentes do "novo teatro" do século XX, De Marinis afirma que ele “ocupa uma posição muito singular, mais uma vez anômala e contra-corrente, entre a vanguarda e a tradição", pois "mostra nexos muito mais estreitos com a tradição e com o passado, em particular polaco, do que com a cultura das vanguardas européias”. (DE MARINIS, 1987, p. 100).

Para Osinski (1993), Grotowski "nunca foi em essência um artista moderno", pois como pesquisador e artista, nas diferentes etapas de seu percurso, buscou "as leis imutáveis, as formas eternas do mundo", aquilo que era unitário nas culturas. Conforme Flaszen, o que o Teatr-Laboratorium realizava era mais coerente com a "retaguarda", do que com a vanguarda: "nossa atividade pode ser compreendida como uma tentativa de restituição

\footnotetext{
${ }^{1}$ Texto originalmente apresentado no curso de mestrado na Universidade de Santa Catarina em fevereiro de 2009, com breves atualizações.

${ }^{2}$ Melissa Ferreira é mestre em teatro pelo Programa de Pós-Graduação em Teatro pela Universidade do Estado de Santa Catarina, autora da dissertação "Mitologia e Ascese: Jerzy Grotowski além do teatro".
} 
dos valores arcaicos do teatro. Não somos modernos, pelo contrário, somos totalmente tradicionais. [...] Acontece assim, que o mais surpreendente sejam as coisas que alguma vez já existiram. E estas nos surpreendem, pela novidade, tanto mais forte, quanto mais profundo seja o poço do tempo que nos separa delas" (FLASZEN apud OSINSKI, 1993, p. 112).

Grotowski relaciona-se com o passado realizando o que Durand denomina de "comparativismo sincrônico" (GARAGALZA, 1990, p. 98), pois sua busca não se dirige na direção de "descobrir" ou inventar algo novo, nem de resgatar com fidelidade histórica um tema do passado. Sua pesquisa está direcionada para "o jogo dos eternos retornos", ou seja, para tudo aquilo que ressurge do passado e tem força e vitalidade no imaginário simbólico de um povo, de uma cultura, no caso, especificamente a polonesa.

Grotowski considerava-se produto da sua tradição:

Penso que a cada momento em que não mentimos para nós mesmos, retomamos contato com esta tradição. Não adianta, porém, buscar um contato consciente. A tradição age de modo real quando é como o ar que se respira - sem pensar nele. Se alguém deve forçarse, fazer esforços compulsivos para aferrar-se a ela, mostrá-la com ostentação - isso significa simplesmente que essa tradição já não está viva nele. Ora o que não é vivo em nós não vale um ato, pois este não será verdadeiro (GROTOWSKI, 1974).

A mais importante tradição com a qual Grotowski teve um contato profundo e constante no período em que realizou espetáculos, segundo De Marinis, foi o drama romântico polaco, com autores como Adam Mickiewicz (1798-1855), Stanislaw Wyspianski (1869-1907), e Juliusz Slowacki (18091849), os mais importantes artistas do romantismo polonês.

A escolha pela dramaturgia polaca do século XIX, obviamente, não se deu por acaso, mas pela identificação com aquela forma de "sentir o mundo", que produziu posteriormente, como apontou o crítico polonês Konstanty Puzyna, uma semelhança com os modos de representar nos seus espetáculos: "tanto nos dramas polacos do século XIX como nos espetáculos de Grotowski se avança mediante mudanças bruscas, contrastes violentos, verdadeira contraposição de contrários no melhor estilo barroco: sublime/ ridículo, bondade/ crueldade, dotes visionários/ realismo, apoteose/ burla […]” (DE MARINIS, 1987, p. 102).

A escolha dos textos no Teatro Laboratório procurava satisfazer a busca por conteúdos simbólicos significativos na cultura polonesa, ou seja, os arquétipos e temas míticos fundamentais capazes de estabelecer associações 
psicofísicas nos atores e espectadores. Os textos eram remodelados de acordo com a identificação e a exaltação do mito fundamental presente na dramaturgia. Porém, apesar da manipulação e aparente dessacralização dos textos da dramaturgia romântica polaca, De Marinis concorda com Puzyna que observa que as versões dirigidas por Grotowski respeitam a Weltanschaunng ${ }^{3}$ daquelas obras, o que, como veremos adiante, nos revela o envolvimento de Grotowski com a resistência cultural ao massacre do imaginário simbólico polonês ao longo da história da Polônia.

O Romantismo foi um movimento artístico e filosófico que surgiu, no final do século XVIII na Europa, como uma resistência ao racionalismo clássico e neoclássico, rejeitando seus preceitos de ordem, equilíbrio e idealização. O início do Romantismo foi marcado por um forte nacionalismo, já que a Europa passava por grandes revoluções que marcavam o fim dos governos despóticos e o início do liberalismo político com a consolidação dos estados nacionais.

Na Polônia, o movimento romântico fez nascer grandes heróis nacionais. Além das inúmeras invasões e desmembramentos, que marcaram profundamente a história e a cultura polonesa, o século XIX foi um momento de inúmeras desilusões políticas para o povo polonês que culminou com o exílio de intelectuais e artistas em vários países da Europa, dentre eles, Frédéric Chopin (1810-1849), Slowacki, Wyspiánski e Mickiewcz, que se tornou um herói do nacionalismo polonês.

O movimento romântico dos artistas poloneses foi intensificado por um sentimento de nostalgia nacionalista dos exilados, que encontravam nos símbolos e dramas nacionais, na tradição folclórica polaca e na alma popular, os temas e meio de expressão do nacionalismo, por uma pátria que nunca existiu.

Este espírito revolucionário e ao mesmo tempo nostálgico parece ter sido a forma de "sentir o mundo" romântica com a qual identificava-se Grotowski, afinal na metade do século XX, depois de duas grandes guerras mundiais que devastaram o país e sob o comando russo, a Polônia não vivia uma situação muito diversa do que a realidade dos artistas do século anterior. Segundo Eugenio Barba, Grotowski sabia de memória fragmentos das obras românticas nacionalistas e constantemente descrevia a insurreição contra os russos e o exílio dos intelectuais: "estava obcecado pela Polônia, mas seu patriotismo não era nacionalismo, era orgulho dos artistas que não haviam se deixado quebrar nem submeter. Passava horas inteiras explicando-me episódios da história e literatura polacas. Estava apaixonado pelos grandes autores românticos Slowacki, Norwid e sobre tudo Mickiewicz" (BARBA, 2000, p. 54). 
Se em toda a Europa o depauperamento dos símbolos dogmáticos na Reforma e Contra-reforma, como afirma Jung, provocou uma sensação coletiva de desgarramento, na Polônia, tornou-se ao longo do tempo, não uma sensação, mas uma situação real. Pois tão ou mais grave do que as invasões, os desmembramentos e as mortes em massa, foi o massacre do imaginário simbólico da cultura polonesa. Para entendermos isso, não é necessário descrever toda a história da Polônia, basta tomarmos como exemplo, o passado recente, no qual esteve inserido Grotowski.

\section{A resistência ao massacre do imaginário simbólico polonês}

Na Segunda Guerra Mundial, a Polônia sofreu um duplo ataque, após um Pacto de Não-Agressão assinado entre Alemanha e União Soviética, que pretendiam dividir o território polonês. Entre 1939 e 1945 foram mortos cerca de seis milhões de poloneses e mais de quinhentos mil foram deportados para a Sibéria, entre eles, funcionários públicos, nobreza e padres. Com o fim da Segunda Guerra, a Polônia ficou sob forte controle da União Soviética até 1981, num regime totalitário que usava de todos os artifícios para se manter no poder. E o principal deles, segundo o polonês Bronislaw Baczko, foi a manipulação da memória coletiva:

Tanto na ficção como na realidade, a intenção totalitária é fundamentalmente a mesma: garantir ao poder o controle das mentalidades, emuito particularmente, da memória coletiva considerada como uma peça mestra. As técnicas desse controle são essencialmente as mesmas: rigorosa censura de qualquer informação sobre o passado; supressão de certos fatos históricos, fabricação de "fatos" novos; permanente atualização das representações do passado em função das necessidades políticas e ideológicas do presente; fabricação de novas mitologias históricas, [...] (Baczko, 1991, p. 159).

Segundo Baczko, desde 1944, a "propaganda” comunista tratava de legitimar, por meio da construção de um passado fictício, as relações entre a Polônia e a União Soviética, ou seja, "relação de dependência política, militar e econômica que a propaganda exaltava como uma aliança livre, fundada na amizade entre os povos, como a única garantia real da independência da Polônia, de sua gloriosa marcha até o socialismo, [...]” (Baczko, 1991, p. 162).

Esta operação da propaganda comunista queria garantir na história polaca, como afirma o autor, "uma estranha coerência”. Mas esta coerência só poderia ser imposta às custas da amputação de enormes pedaços do passado polonês. 
Na história das relações entre a Polônia e a União Soviética, divulgada pela "propaganda” comunista, o fim do século XVIII e todo o século XIX formam um período duvidoso, pois é justamente o período em que a Rússia levou o melhor nas insurreições nacionais de 1794, 1830 e 1863, contra a ocupação russa, e é também a época em que a grande literatura romântica consolidou toda uma mitologia nacional: "em um país privado de sua independência, que não dispunha nem de estruturas estatísticas nem de ensino nacional, corresponde a literatura e a memória coletiva alimentando-se mutuamente, ao lado da religião, garantir a identidade nacional”. (Baczko, 1991, p. 163).

A propaganda russa buscava reforçar toda a tradição anticlerical e anticatólica do passado polaco, pois não só o drama romântico representava um ponto de resistência da cultura polonesa contra a dominação russa, mas também a Igreja Católica, presente na Polônia desde o ano de 966: “[ ...] representava também um território de memória livre, que escapava ao domínio totalitário, de uma memória e de uma tradição vivas, arraigadas na fé, conservadas e reproduzidas por símbolos e práticas, como por exemplo, as peregrinações da Virgem Negra de Czenstochowa ou os velhos cantos religiosos e patrióticos ao mesmo tempo" (Baczko, 1991, p. 164).

Por entender a força da Igreja Católica na cultura polonesa, porém, o Partido procurava manter uma boa relação com a religião: "na Polônia socialista se podia ser religioso, professar livremente a própria fé, frequentar as onipresentes igrejas e paróquias. O regime havia conseguido encontrar um modus vivendi com a potente Igreja católica, e os intelectuais e escritores católicos publicavam uma revista que estava entre as melhores daquela época. Mas ser definido como "místico" ou "idealista" significava que o regime te considerava seu opositor" (BARBA, 2000, p. 51). Estas características eram, justamente, as marcas do nacionalismo romântico.

Na segunda metade do século XX, os diversos conflitos que ocorreram na Polônia, como a brutal repressão das greves em Gdansk, a criação do sindicato independente Solidariedade, os movimentos estudantis, e o Outubro Polaco, segundo Baczko, tiveram como objetivo "a reconquista de um espaço simbólico e a reconquista do direito ao passado” do povo polonês.

Foi neste período que o teatro começou a ressurgir também como um espaço de liberdade na Polônia. Conforme Kumiega, o período que vai de 1939 a 1956, foi de total estagnação no mundo teatral polonês. Além do fechamento dos teatros durante a guerra, e dos inúmeros artistas mortos ou presos, nos anos pós-guerra, houve, por parte do regime socialista, a implantação do Realismo Socialista como estilo oficial do regime. Esta imposição, aliada a uma política administrativa centralizada, acabou por destruir "cada forma 
de autonomia criativa, componente essencial para um teatro de valor". (KUMIEGA, 1989, p. 19). Porém, depois da metade dos anos cinquenta, com a flexibilização das restrições do regime, e a tendência à descentralização do poder, o teatro ganhou nova vida na Polônia. Os diretores dos principais teatros poloneses passaram a ter oportunidade de experimentar um estilo próprio. Segundo Kumiega, apesar da difusão das tendências das vanguardas teatrais ocidentais terem ocorrido com as políticas de abertura do regime, elas trouxeram pouca contribuição artística para o teatro polaco, já que só vieram reforçar sua tradição, como o movimento do teatro do absurdo, por exemplo, que já existia na Polônia, com os autores Stanislaw Ignacy Wietkiewicz (18851939) e Witold Gombrowicz (1905-1969). Este momento de maior liberdade artística, porém, tornou possível o tipo de pesquisa totalmente personalizada que Grotowski realizou no seu teatro.

Com o objetivo de "testar" valores tradicionais da cultura polonesa, Grotowski realizou um trabalho de intervenção nos textos nunca antes visto na história do teatro. Na primeira metade do século, Stanislavski já havia experimentado mudar o sentido de uma obra dramática através da interpretação particular do texto, e Meyerhold, através da reestruturação do texto, realizou quebras nas sequências das cenas e produção de simultaneidades. Grotowski, porém, "triturou" e remodelou os textos conforme as exigências estabelecidas pelo trabalho do ator, realizando o que ele denominou de dialética da apoteose e do escárnio, ou da adoração e da profanação, buscando uma experiência verdadeiramente viva e coletiva para atores e espectadores. Como descreve Jean-Jacques Roubine,

Essa experiência coletiva tem, portanto em primeiro lugar, uma dimensão diacrônica: ela provém de uma memória cultural. Mas ao mesmo tempo ela deve assumir uma dimensão sincrônica, para não correr o risco de significar um retorno ao tradicional teatro de celebração cultural. Ela deve pertencer à memória pessoal do ator e do espectador. Daí o movimento em mão dupla que anima a busca do ator grotowskiano e institui uma verdadeira dialética da adoração e da profanação (os termos são de Grotowski): os mitos em que está enraizada a memória coletiva são retomados, reativados - esta é a adoração; ao mesmo tempo, são confrontados com uma realidade existencial contemporânea que pode contestá-los, pulverizá-los - eis a profanação (ROUBINE, 1998, p. 72).

Após um breve período em que trabalhou com alguns textos da vanguarda européia, como As Cadeiras, de Ionesco, Grotowski buscou nos clássicos os temas e os conteúdos que fossem vivos na sua cultura, conforme 
Barba: "Grotowski afrontou os clássicos, com a persistente convicção de que contém um arquétipo, uma situação fundamental da condição humana”. (BARBA, 2000, p. 44). Os conteúdos míticos, segundo Grotowski, deveriam funcionar como o elo de ligação entre os participantes do ato teatral:

Para que o espectador seja estimulado a uma auto-análise, quando confrontado com o ator, deve existir algo em comum a ligálos, algo que possa ser desmanchado com um gesto, ou mantido com adoração. Portanto, o teatro deve atacar o que se chama de complexos coletivos da sociedade, o núcleo do subconsciente coletivo, ou talvez do superconsciente (não importa como seja chamado) aqueles mitos que não constituem invenções da mente, mas que são, por assim dizer, herdados através de um sangue, uma religião, uma cultura e um clima (GROTOWSKI, 1987, p. 36).

Grotowski buscou as fontes da tradição mítica polonesa nos grandes representantes da resistência ao massacre do imaginário simbólico e da memória social da Polônia: o drama romântico do século XIX e a tradição cristã, que o totalitarismo soviético tentava apagar.

Na tradição cristã Grotowski buscou inspiração para a nomenclatura com a qual nomeava seu trabalho, como ator-santo, profanação, confissão, expiação, redenção, comunhão, transiluminação. Para o teórico Christopher Innes, é natural que um teatro que rejeitasse a sociedade do século XX, materialista e racionalista, buscasse uma outra escala de valores, o da fé religiosa, "enquanto continua rejeitando a religião organizada como cúmplice do status quo". Porém, mesmo quando as produções de Grotowski "atacam o que é sagrado na forma de cristianismo organizado, sua escolha de textos sempre esteve dentro da "grande tradição” (INNES, 1992, p. 174).

Alguns dos dramas do romantismo polonês que foram encenados por Grotowski continham, em si mesmos, os temas míticos e a simbologia da tradição cristã, como Akropolis, de Wyspiánski, que se passa na catedral da cidade polonesa de Cracóvia onde, em uma noite, personagens se destacam das tapeçarias para recitar trechos bíblicos, sobre a ressurreição de Cristo.

Akropolis (1962), de Grotowski, porém, aplicando a "dialética da exaltação e da profanação”, é um exemplo contundente do confronto entre valores tradicionais e uma experiência contemporânea e/ou vivência pessoal. Originalmente situada na catedral da Cracóvia, a Akropolis de Grotowski situa-se num campo de concentração: 
Para Grotowski, a idade contemporânea começa na segunda metade do século XX. Daí sua experiência ser muito mais cruel que a de Wyspianski, e os valores do velho século da cultura européia são submetidos a um severo teste. Seu ponto de fusão não é mais o tranqüilo local da velha catedral, onde o poeta sonhou e meditou na solidão sobre a história do mundo. Eles se chocam no clamor de um mundo extremado, em meio a uma confusão poliglota na qual foram projetados pelo nosso século: num campo de extermínio. Seus personagens reordenam os grandes momentos da nossa história cultural: mas revivem não as figuras imortalizadas nos monumentos do passado, porém as fumaças e emanações de Auschwitz (FLASZEN In: GROTOWSKI, 1987, p. 53).

A apenas dezessete anos do fim da Segunda Guerra Mundial, e a cem quilômetros de Auschwitz, Grotowski retomou uma experiência viva na memória dos atores e dos espectadores. Segundo Roubine, "com isso, entram em choque as duas concretizações antagônicas do pensamento e da civilização do Ocidente” (1998, p. 27). Através da exaltação dos mitos contidos na obra, recuperam-se valores humanos cristãos como o amor, a caridade, a abnegação, que são simultaneamente, afirmados e questionados, ao confrontá-los com uma das experiências mais desumanas da história da humanidade: os campos de extermínio do nazismo alemão.

Em Akropolis, segundo descreve Flaszen, os personagens mudam de sexo e se transformam em objetos. Helena, da mitologia grega, amor de Paris, no espetáculo de Grotowski, é um homem. Jacó dirige seu amor para sua noiva, uma chaminé enrolada em um pedaço de véu. O Salvador, Cristo, "é um cadáver sem cabeça, azulado, completamente despedaçado, horrível reminiscência do campo de extermínio” (FLASZEN In: GROTOWSKI, 1987, p. 58).

O tex to Os antepassados, de Adam Mickiewicz, foi proibido em diversos momentos da história da Polônia, por apresentar forte conteúdo anti-soviético. O texto foi escrito por Mickiewicz no exílio, em 1832, e era considerado símbolo do nacionalismo polonês. Em 1968, data dos grandes movimentos estudantis na Europa e no mundo, a proibição do texto de Mickiewicz, fez com que estudantes na Polônia realizassem as primeiras manifestações, no dia 08 de março, antes mesmo do "maio francês". Estes movimentos fizeram com que aproximadamente vinte mil pessoas abandonassem o país e treze mil e quinhentas perdessem a nacionalidade entre 1968 e 1970, segundo documentos dos arquivos do país. Sete anos antes, em 1961, Os Antepassados, foi o primeiro texto polonês encenado por Grotowski no Teatr 13 Rzedów. Grotowski buscava aliados no passado da Polônia, com que pudesse dialogar, e reencontrar a liberdade perdida: 
Sempre encontramos aliados e sempre encontramos inimigos a quem combater. Se você está diante de um sistema social extremamente rígido, você tem que consertá-lo, você tem que reencontrar sua própria liberdade, você tem que reencontrar seus aliados. Talvez eles estejam no passado. Pois, falo com Mickiewicz. Mas falo dos problemas de hoje. E também do sistema social no qual vivi na Polônia durante quase toda minha vida. Esta aqui tem sido minha atitude: não é para fazer discursos que trabalho, e sim, para aumentar a ilha de liberdade; minha obrigação não é fazer declarações políticas, e sim fazer buracos no muro. As coisas que me foram proibidas devem ser permitidas depois de mim; as portas que me foram fechadas, com duas voltas, devem ser abertas; tenho que resolver o problema da liberdade e da tirania através de medidas práticas. Isto quer dizer que minha atividade deve deixar rastros, exemplos de liberdade (GROTOWSKI, 1993, p. 69).

Grotowski, segundo Kumiega, teve um curto período de efetiva participação na vida política da Polônia, pouco conhecido, em 1957, após o "Outubro Polaco", participando ativamente das organizações políticas juvenis. Após este período, Grotowski se afasta da política, porém, anos depois, ao se referir àquele período diz: "queria ser um mártir político, um entre os mais importantes. Era fascinado por Gandhi a ponto de querer ser como ele" (GROTOWSKI apud KUMIEGA, 1989, p. 16). Seu afastamento efetivo dos movimentos políticos poloneses talvez tenha levado à falsa idéia de uma postura apolítica aos seus contemporâneos, mas segundo Barba, cada passo de Grotowski, do Teatr 13 Rzedów ao Teatr-Laboratorium, era pensado com o objetivo de defender o "essencial" do controle soviético. "Grotowski me explicava com todos os detalhes como pensava em se comportar, quais seriam as prováveis e diversas reações, com quem e até que ponto recorrer ao patriotismo polaco para ser "ideologicamente incorreto" sem criar problemas de alto nível com os russos. Eu era testemunha do nascimento e do desenvolvimento de seus processos mentais, que se transformavam em jogadas estratégicas para defender o "essencial"” (BARBA, 2000, p. 51).

Naquele momento, acima de tudo, podemos concluir que "o essencial” era conseguir manter um espaço de liberdade. Para, assim, poder continuar a fazer os espetáculos, poder manter o grupo, o treinamento e os temas que, segundo Barba comentando o espetáculo Studim o Hamlecie, não tinham nada de apolíticos:

Todos com um subtexto explicitamente político, todos vinculados com a história da Polônia: o intelectual que quer atuar (Dzyady e Kordian), que se opõe a uma vontade mais potente (Dr. 
Faustus); a coletividade, que arremete contra o outsider leal aos seus princípios. São temas que reaparecerão em O Príncipe Constante, onde os atores, sobretudo Ryszard Cièslak, encarnarão de uma maneira incrivel a intensidade do rechaço de uma sociedade e seus valores (BARBA, 2000, p. 98).

A mudança de nome de Teatr 13 Rzedow para Teatr-Laboratorium 13 Rzedów, que aparece pela primeira vez no programa do espetáculo Akropolis, foi um exemplo de um ato político em defesa do "essencial”. Em 1962, Grotowski preencheu um formulário enviado pelo Ministério da Cultura polonês, no qual assinalou "laboratório" para classificar seu teatro, por não se encaixar em mais nenhuma opção. Porém, imediatamente se deu conta da importância deste ato, pois, ao classificar seu teatro como laboratório poderia justificar a longa duração do processo de preparação dos espetáculos e o número restrito de espectadores. Além disso, o termo se referia a antecedentes históricos, os laboratórios de Stanislavski, que era o modelo artístico do teatro soviético.

A ação teatral de Grotowski, segundo Barba, tinha um duplo sentido. Se por um lado, o espetáculo era para ele, um ritual laico, inspirado na tradição iniciada por Antoine, Stanislavski e Reinhart, que implica na "osmose espacial” de atores e espectadores, e os faz "meditar ativamente sobre as feridas da condição humana”; por outro lado, além do valor artístico e social do espetáculo, havia no teatro uma "tensão secreta" no sentido da religiosidade: "a representação é um ato de transgressão que permite derrubar nossas barreiras, transcender nossos limites, encher nosso vazio, realizar-nos, entrar no território do sacrum. (...) A transgressão de Grotowski foi aplicada aos valores da tradição que nos transmitem os textos clássicos, às maneiras de conceber e praticar o teatro, à concepção de uma arte utilitária ou simplesmente ideológica”. (BARBA, 2000, p. 46).

Esta forma de fazer e pensar o teatro era extremamente subversiva num regime socialista. Conforme Barba (2000, p. 46), os soviéticos entenderam que não se tratava de um teatro formalista, mas de uma força que crescia bem no centro de sua manipulação do mundo, rejeitando-a: "Era uma rejeição simbólica, a única arma do artista”. Para Barba, era revoltante ouvir e ler as acusações dos artistas "comprometidos" da época, que tachavam Grotowski de apolítico: "Tais atitudes revelavam uma cegueira absoluta do extremismo rebelde do pensamento e prática teatral de Grotowski, como também sua luta e estratégia para defender sua própria verdade sem trair e sem se deixar esmagar" (BARBA, 2000, p. 46).

Na Polônia socialista não era permitido ter passaporte, nem sair do país, a não ser com um convite oficial e todas as despesas pagas pelo evento. Os únicos espetáculos que viajaram ao exterior foram Akropolis, O Príncipe Constante e Apocalypsis cum Figuris. 
As idéias de Grotowski, através de seus textos, principalmente o Novo Testamento do Teatro, foram difundidas na Europa por Eugenio Barba, entre 1963 e 1964, numa estratégia elaborada para fazer parecer aos críticos e às hostis autoridades do regime que Grotowski era reconhecido no exterior. Barba, como italiano com passaporte e acesso livre a outros países, realizou suas viagens com o dinheiro da bolsa de estudos que recebia do governo italiano para estudar na Polônia. Através destas viagens, Grotowski teve seus primeiros convites para publicações e apresentações no exterior. Dentre as cidades visitadas por Barba estão Viena, Roma, Zurique, Basilea, Genebra, Paris, Estocolmo, Copenhague e Oslo. Nestas cidades Barba visitou críticos, artistas, poetas, escritores, editores de revistas e livros, diretores de teatros e instituições e universidades. Em Zurich, foi ao Instituto Jung, onde deixou artigos com o diretor da instituição, James Hillman. Além das visitas, Barba enviou cartas a pessoas de várias partes do mundo através dos contatos conseguidos na viagem, dentre eles, Richard Schechner, Fernando Arrabal e Mircea Eliade. Esta jornada era para ele uma missão: “O desejo de proteger a obra de Grotowski, a quem queria bem infinitamente, e esse pequeno teatro que para mim era ao mesmo tempo lar, aventura, paixão e religião, se converteu em um desafio permanente, uma obsessão, uma necessidade” (BARBA, 2000, p. 73).

Em abril de 1964, na Noruega, quando Barba retornava de uma destas viagens, foi impedido de embarcar para Polônia porque teve seu visto recusado com argumento de que era persona non grata no país, tendo que deixar para trás tudo que tinha: roupas, livros, discos, notas de trabalho, amigos e o trabalho com o Teatr-Laboratorium. Em outubro deste mesmo ano, Barba fundou em Oslo, junto com jovens atores, o Odin Teatret, que dois anos mais tarde, organizou a primeira viagem internacional do Teatr-Laboratorium, com o espetáculo $O$ Príncipe Constant.

Por conta do controle soviético, o espetáculo Estudo sobre Hamlet(1964) teve problemas com a censura, tendo sido apresentado poucas vezes e depois retirado da lista oficial de espetáculos do Teatr-Laboratorium, sendo considerado o espetáculo “judeu” do grupo. Por conta da censura deste espetáculo, o teatro começou a receber ameaças de ser fechado pelas autoridades de Opole, com a justificativa de que era irrelevante para a cidade, pela falta de público.

Como já vimos com Baczko, a censura foi um dos métodos usados pelos soviéticos para manipular a memória social da Polônia. Segundo Barba, "os motivos de censura podiam variar em função das circunstâncias: tendências formalistas ou decadentes, virulência anti-religiosa (nos períodos em que o Partido queria manter boas relações com a Igreja católica), alusões antisoviéticas, idealismo ou cosmopolitismo" (BARBA, 2000, p. 69). 


\section{O fim do Teatr-Laboratotium}

Em março de 1964, o Ministério da Cultura polonês enviou uma comissão para avaliar a atividade do Teatr-Laboratorium, e graças à defesa de membros da comissão, principalmente do crítico teatral e redator Konstanty Puzina, o teatro permaneceu funcionando. Puzina montou uma estratégia para defender o Teatr-Laboratorium: pediu que diversas personalidades da área teatral falassem mal publicamente do trabalho de Grotowski, pois sabia que, assim, seriam escolhidas para integrar a comissão de avaliação mandada pelo governo. Após visitarem o teatro, porém, anunciaram que o trabalho tratavase de um fenômeno excepcional e que deveria receber todo o apoio possível. (BARBA, 2000, p. 154).

Apesar de todos os esforços o Teatr-Laboratium 13 Rezedów foi fechado pelas autoridades de Opole, pressionados pelas autoridades centrais da Varsóvia, no final de 1964. A transferência do Teatr-Laboratorium para a cidade universitária de Wroclaw, portanto, não foi realizada por decisão do grupo, mas foi a saída encontrada para manter o trabalho.

As autoridades municipais de Wroclaw, com o intuito de salvar a companhia, providenciam o transporte e a abertura do teatro em sua cidade. Opole, na época, tinha sessenta mil habitantes, enquanto Wroclaw era uma cidade de meio milhão de habitantes. Em Wroclaw, porém, as estratégias para lidar com a censura continuaram, aliás, por todo o tempo em que Grotowski esteve na Polônia.

Com a situação tensa na Europa, em 1969, após os movimentos estudantis, a invasão da Tchecoeslováquia e a nova perseguição aos judeus e artistas na Polônia, Grotowski temia ser preso, e que, no cárcere, e sob violência física, não conseguisse manter sua dignidade até o fim. Por isso, pediu em carta a Eugenio Barba que lhe conseguisse veneno, para no caso de ser preso, por fim à própria vida. (BARBA, 2000, p. 205).

Grotowski não foi preso na década de sessenta, nem na década seguinte, porém, em janeiro de 1982, teve de abandonar a Polônia com o decreto da Lei Marcial no país, para instalar-se em Holstebro, num pequeno quarto do Odin Teatret. Após um período na Itália, e no Haiti, transferiu-se para os Estados Unidos, onde permaneceu como refugiado até 1985.

A situação em que se encontrava a Polônia, com o fechamento dos cinemas e teatros, racionamento de comida, a proibição de reuniões em grupos numerosos e de deslocamentos sem autorização, fez com que o TeatrLaboratorium encerrasse suas atividades em Wroclaw. Em 1984, o jornal local de Wroclaw Gazeta Robotnicza, publicou o comunicado enviado pelo grupo: 
Há algum tempo o nosso grupo praticamente desistiu de atuar como um grupo criativo. Tornou-se uma cooperativa de indivíduos que conduzem uma pesquisa independente de múltiplas atividades. Isto está na natureza das coisas. Como grupo Teatro Laboratório, acreditamos ter realizado nesses anos aquilo que devíamos realizar. Nós mesmos ficamos surpresos de ter continuado em grupo durante um quarto de século - transformando-nos constantemente, inspirando-nos uns aos outros, irradiando aos outros a nossa energia comum.

$A$ idade criativa de um grupo e a idade criativa de um indivíduo não são a mesma e idêntica coisa. Entre nós, alguns correrão o rico de uma vida artística totalmente independente, enquanto outros, talvez queiram continuar a trabalhar juntos no âmbito de alguma nova estrutura institucional. Cada um de nós sabe bem que as nossas origens se remetem a uma fonte comum, que se chama Jerzy Grotowski, e ao seu teatro.

(...) Depois de ter caminhado juntos por vinte e cinco anos, nos sentimos próximos um do outro justamente como no início, independentemente do lugar no qual cada um de nós se encontra neste momento: todavia também nos transformamos. Daqui para frente, cada um deve aceitar, a seu modo, o desafio lançado pela própria criatividade e pelos tempos em que vivemos.

O grupo do Teatro das Treze Filas, do Instituto de Pesquisa do ator, do Instituto do Ator, em outras palavras, o grupo do Teatro Laboratório, decidiu dissolver-se em 31 de agosto de 1984, depois de exatamente vinte e cinco anos.

A nossa gratidão vai a todos aqueles que nestes anos nos ajudaram, acompanharam e nos concederam confiança, em Opole, em Wroclaw, na Polônia e no mundo (In KUMIEGA, 1989, p. 161).

Através desta declaração assinada pelos membros fundadores do TeatrLaboratorium, Ludwick Flaszen, Rena Mirecka, Zygmunt Molik e Ryszard Cieslak, o grupo oficialmente se dissolve. Grotowski transforma-se na fonte comum que os liga. Mesmo, Flaszen, que era mais velho e mais experiente, remete-se ao trabalho desenvolvido por eles, ao longo dos vinte e cinco anos, como sendo "o teatro de Grotowski". No momento de conclusão do TeatrLaboratorium, as origens do grupo não se remetem mais à tradição polonesa, mas à mítica figura de Jerzy Grotowski. 


\section{Referências bibliográficas}

Baczko, Bronislaw. Los imaginarios sociales: Memorias y esperanzas colectivas. Buenos Aires: Ediciones Nueva Visión, 1991.

BARBA, Eugenio. La Tierra de Cenizas y Diamantes: Mi aprendizaje en Polonia. Barcelona: Ediciones Octaedro, 2000.

DE MARINIS, Marco. En busca del ator y del espectador - Compreender el teatro II. Buenos Aires: Gelerna, 2005. . El nuevo teatro, 1947-1970. Barcelona: Paidós, 1987.

GARAGALZA, Luis. La interpretación de los símbolos - hermenéutica e lenguaje en la filosofía actual. Barcelona: Antrophos, 1990.

GROTOWSKI, Jerzy. Tu eres hijo de alguien. In: Máscara - Cuaderno iberoamericano de reflexion sobre escenologia, México:, ano 3, n. 11-12, p. 69-75, jan. 1993.

Civilização Brasileira, 1987.

Em busca de um teatro pobre. 3 ed. Rio de Janeiro: "Dia santo" e outros textos. Trad. José Ronaldo Faleiro a partir da edição francesa [“Jour Saint” et autres textes. Traduit du plonais par Georges Lisowski et l'auteur. Paris: Gallimard, 1974].

INNES, Christopher. El teatro sagrado - El ritual y la vanguardia. México: Fondo de Cultura Económica, 1992.

KUMIEGA, Jennifer. Jerzy Grotowski. La ricerca nel teatro e oltre il teatro 19591984. Firenze: La casa Usher, 1989.

OSINSKI, Zbgniew. Grotowski traza los caminos: del drama objetivo (19831985) a las artes rituales (desde 1985). In: Máscara - Cuaderno iberoamericano de reflexion sobre escenologia, México: ano 3, n. 11-12, p. 96-113, jan. 1993.

ROUBINE, JJ. A linguagem da encenação teatral. 2 ed. Rio de Janeiro: Jorge Zahar Ed., 1998. 